\title{
Selection of an Inert Gas System for the Transportation of Direct Reduced Iron
}

\author{
Devran Yazir $\mathbb{D},{ }^{1}$ Bekir Sahin $\mathbb{D}^{2},{ }^{2}$ and Murat Alkac $\mathbb{D}^{1}$ \\ ${ }^{1}$ Surmene Faculty of Maritime Sciences, Karadeniz Technical University, Trabzon, Turkey \\ ${ }^{2}$ Department of Logistics Management, International Maritime College Oman, Sohar, Oman
}

Correspondence should be addressed to Devran Yazir; dyazir@ktu.edu.tr

Received 6 May 2021; Revised 16 September 2021; Accepted 12 October 2021; Published 16 November 2021

Academic Editor: Rahib Abiyev

Copyright (C) 2021 Devran Yazir et al. This is an open access article distributed under the Creative Commons Attribution License, which permits unrestricted use, distribution, and reproduction in any medium, provided the original work is properly cited.

Direct reduced iron (DRI) can create significant risks such as ignition, explosion, and fire because of the oxidation reaction in case when DRI undergoes spontaneously heating and comes in contact with oxygen or water. For this reason, the transportation of DRI is classified as a dangerous task of which the inert process should be done in the ship's holds. Many studies have been conducted on the production and production stages of DRI and other areas of use of inert gas, but no studies have been conducted on the safe transportation of this cargo by ships. This study analyzes the criteria and alternatives for selecting the inert gas system for the benefits of investors and shipowners in the shipping industry. The intuitionistic fuzzy TOPSIS (IF-TOPSIS) method is implemented to conduct the decision-making process. As a result of this study, preferences for candidate inert gas systems are modelled. Port facility nitrogen generator is selected as the most suitable inert gas system among alternative inert gas systems based on predetermined criteria.

\section{Introduction}

As the distances between countries disappear with globalization and technology, the movement of resources between countries and transportation continues to gain importance day by day. Maritime transport is of great importance in freight transport, as it is more economical than its alternatives and transports larger volumes of cargo at one time. Approximately $84 \%$ of the cargoes transported in world trade are transported by waterways in terms of volume and approximately $70 \%$ in terms of value. Shipping has a much higher share, especially in developing countries [1].

Among the cargoes transported by sea, there are also dangerous cargoes that can cause profound loss of life and material damage in the event of an accident/incident. Direct reduced iron (DRI) cargo is among the dangerous cargoes due to the risks it holds. Various measures should be taken to eliminate or minimize the risks that may be encountered during the transportation of dangerous cargo by sea. In order to eliminate the potential risks of the DRI cargo, there are situations to be considered and measures to be taken in the process of transporting by sea. The first of these measures is to pump inert gas into the DRI cargo warehouses [2].

There are few studies in the literature on the transportation of DRI cargo by sea. Sitov et al. [3] conducted a study to determine safe technological parameters in the process of transporting DRI by sea. They used the mathematical formulation method to investigate the thermophysical models of spontaneous combustion and to determine the parameters of the spontaneous combustion process based on kinetic determination methods. They found that the known thermophysical properties and the height and diameter of the deposition layer were critical values of the DRI cargo. They stated that depending on the level of temperatures, they might cause a fire during the transportation process. While preparing a loading plan, it is the parameters that should be considered during the voyage safety principles for the permissible load height and temperature values in the ship's cargo spaces according to the fire criteria [3]. 
Paswan and Mukherjee [4] conducted a study to solve the burning problem of DRI cargo. They did some experiments in the lab to find the exact cause of DRI burning. The purpose of these experiments was to pinpoint the causes and conditions of combustion. As a result, they stated that the best solution is passivization process (neutralization process on iron). They determined that water is the most important cause. They stated that it is rainy season for 9 months of the year in the delta region of Nigeria and it is necessary to be careful against rain in handling DRI cargo due to sudden rains, and temperature monitoring is essential and all precautions should be taken against warming during the handling process [4].

It is stated in the IMSBC Code that the warehouses should be inerted and the DRI load should be transported [2]. As DRI cargo is solid cargo, it is transported by dry cargo ships. However, inert gas systems are systems used in ships carrying petroleum products and liquid chemical cargo. Inert gas systems are not equipped on dry cargo ships. Despite this situation, safe transportation conditions should be established by inerting to eliminate or minimize the dangers in DRI cargo transportation [2].

This paper deals with selecting an inert gas system for the transportation of DRI safely by using the intuitionistic fuzzy TOPSIS (IF-TOPSIS) method. In this study, a selection process is conducted based on five different inert gas systems along with the predetermined five criteria by using the IFTOPSIS method. This study contributes to better understanding an inert gas system for the transportation of direct reduced iron, introducing new technologies and analyzing selection criteria. In Section 2, an overview to the inert gas system is provided. A literature review is given in Section 3. The proposed methodology is introduced in Section 4. In Section 5, the particulars of the criteria and alternatives are explained. Application is given in Section 6 which analyzes and discusses the results and gives the future directions. Finally, the last section concludes the paper.

\section{An Overview of Inert Gas System}

Inert gas is a type of gas that is used today to prevent hazards such as flammability, explosion, and fire on ships carrying dangerous liquid cargo in sea transportation. Also, it is a gas that contains oxygen that does not support combustion. Inert gas can be obtained from the exhaust gas from the ship's main and auxiliary boilers, from inert gas generating systems, or from an independent inert gas generator. It contains $83 \%$ nitrogen, $12-14 \%$ carbon dioxide, $2-4 \%$ oxygen, and $50 \mathrm{ppm}$ sulfur dioxide, and its density is $1.044 \mathrm{gr} /$ $\mathrm{cm}^{3}$ (Table 1) [5]. In ships carrying dangerous goods, the oxygen gas level is reduced below certain values by sending (pressing) inert gas to the tanks or holds during the loading, transportation, and evacuation of the cargo and the dangers are eliminated. These oxygen levels vary according to the type of load and the type of volatile and flammable gas it emits. For example, for a load that emits hydrocarbon gas, the maximum oxygen level is $11 \%$ so that the gas it emits does not react with oxygen. On the other hand, in accordance with the International Life Safety Convention (SOLAS
1974), for a load emitting hydrogen gas, this oxygen value should be a maximum of $5 \%$ [5].

Vessels carrying dangerous goods contain intense amounts of flammable and volatile gas in the tank or warehouse atmosphere. When these gases are in contact with oxygen, which is the caustic gas, and the appropriate temperature environment is provided, a fire occurs. This combination is also called the fire triangle [6]. To break this danger chain, it is necessary to remove at least one of these elements from the environment. This is often impossible due to the load transported. There are not many options for temperature either. The simplest and easiest way to prevent hazards such as fire, flaming, or explosion from occurring would be to remove oxygen from the environment [5]. Inert operations are performed as a method of removing oxygen from the environment to eliminate these dangers on ships carrying dangerous goods.

Steel production with the direct reduction method gains an increasing importance. Besides, different production technologies are developed with various research, applications, and methods. The most important factors in the production costs of direct reduced iron (DRI) (sponge iron), a porous product obtained by direct reduction, are energy and raw materials. For this reason, sponge iron is produced in countries such as India, Iran, Saudi Arabia, Russia, Mexico, and Venezuela where natural gas reserves are rich (Figure 1) [7]. DRI is a black or grey metallic and porous product produced as a by-product of iron processing and production processes. Its average dimensions are around $6.35 \mathrm{~mm}$, and it does not exceed $12 \mathrm{~mm}$. The stowage factor (stacking factor/volume of 1 ton of cargo) is $0.30-0.54$ cubic meter/ton. DRI is also called sponge iron. It is a product obtained by direct reduction by removing oxygen from the solid iron ore by hydrogen and carbon monoxide derived from natural gas or coal. The reducing gas is a mixture of hydrogen $\left(\mathrm{H}_{2}\right)$ and carbon monoxide (CO) gases (Figure 2) (International Iron Metallics Association [9]).

DRI, a highly reduced product transported by bulk/dry cargo ships, tends to re-oxidize, which is an exothermic reaction. After loading in bulk, it may cause an increase in temperature of about $30^{\circ} \mathrm{C}$ due to self-heating. It can create overheating, fire, and explosion risk during its transportation. The DRI cargo reacts with air, freshwater, and seawater to generate hydrogen and heat. Hydrogen is a flammable gas that can form an explosive mixture when mixed with air at concentrations above $4 \%$ by volume. Selfheating of the load can create very high temperatures that can cause spontaneous ignition and explosion. Due to these hazards of DRI cargo, ships that carry DRI should take some measures. The first of these measures is to pump inert gas into the holds and cargo spaces after the covers of the holds loaded with DRI cargo are closed. Due to the characteristics of the inert gas load, which is pressed into the cargo spaces, a possible risk of flammability, explosion, or fire is removed (Table 2) [2].

Appropriate detectors should be available on-board to regularly perform quantitative hydrogen and oxygen measurements during DRI cargo transportation. These detectors must be suitable for use in an oxygen-depleted atmosphere. 
TABle 1: The gases in the content of inert gas and their characteristics.

\begin{tabular}{lcc}
\hline Property & Symbol & Ratio \\
\hline Nitrogen & $\mathrm{N}_{2}$ & $83 \%$ \\
Carbon dioxide & $\mathrm{CO}_{2}$ & $12-14 \%$ \\
Oxygen & $\mathrm{O}_{2}$ & $2-4 \%$ \\
Sulfur dioxide & $\mathrm{SO}_{2}$ & $50 \mathrm{ppm}$ \\
Carbon monoxide & $\mathrm{CO}_{2}$ & Trace \\
Nitrogen oxide & $\mathrm{NO}_{x}$ & Trace \\
Water vapour & $\mathrm{H}_{2} \mathrm{O}$ & Trace (high if not dried) \\
Ash and soot & $(\mathrm{C})$ & Traces \\
Density & & 1.044 \\
\hline
\end{tabular}

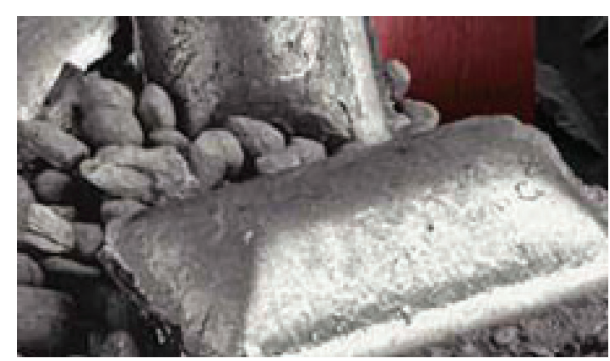

Figure 1: An example of DRI cargo [7].

It must be of a type that is approved to be safe for use in explosive atmospheres. Hydrogen and oxygen concentrations in cargo spaces carrying this cargo should be measured at regular intervals while traveling. Besides, hydrogen and oxygen measurement results should be recorded and kept on-board for at least two years. Oxygen concentration in cargo spaces should be kept below 5\% during the transportation by filling with inert gas. Cargo temperatures should be checked at regular intervals during the transportation. Moreover, the cargo temperature measurements should be recorded and kept on-board for at least two years. Bilge wells should be checked regularly for the presence of water. If water is found in the bilge wells, it should be emptied with a bilge pump and pumped out. Besides, attention should be paid to increasing the frequency of cargo tracking after lousy weather conditions. All measurements should be taken so that the loss of inert gas from cargo spaces is as minimal as possible [2]. A typical inert gas system layout is depicted in Figure 3.

\section{Literature Review}

This study is carried out using the IF-TOPSIS method to select the inert gas system to transport DRI cargo, which is classified as dangerous cargo for the dry bulk cargo ships. In the literature, there are many studies regarding to technical characteristics of DRI. For instance, Bandopadhyay et al. [11] tried to answer the problems of the DRI product stability at varying temperatures, depending on the ambient temperature, and the unknown re-oxidation at temperatures above $200^{\circ} \mathrm{C}$. As a result of the experimental investigations, it was determined that the gas-based DRI oxidizes a little faster at temperatures lower than $720^{\circ} \mathrm{K}\left(446.85^{\circ} \mathrm{C}\right)$. However, they find that at high temperatures above $800^{\circ} \mathrm{K}\left(526.85^{\circ} \mathrm{C}\right)$, the oxidation rate slowed down due to the simultaneous oxidation of carbon. In this context, it is understood that not every temperature increase causes a rapid DRI oxidation.

In another paper, Duarte et al. [12] conducted a study to see that an ENERGIRON plant (DRI technology facility) operating with high pressure and closed system works more economically and environmentally with the HYTEMP Pneumatic Conveying System, reducing dust emissions to both air and sedimentation tanks. The study examines the configuration and economic impact of these green technologies by reviewing this design. After all, the researchers concluded that the ENERGIRON system is a more environmentally friendly system. $\mathrm{Li}$ and Barati [13] aimed to examine the different steps and mechanisms involved in the general melting and decarburization (decarburization) of DRI pellets in slags. By conducting experimental studies, they concluded that the decarburization event occurred due to the reaction between $\mathrm{FeO}$ and carbon in the DRI pellet the reaction between $\mathrm{FeO}$ in the slag and the carbon remaining in the DRI pellet.

It is difficult to determine the effects of inert gas on all ships. So, two premises can be looked at: they could be the type of ship and the deadweight (DWT) tonnage because the more the selection processes increase the more difficult it will be to make an assessment. Thomas and Skjong [14] conducted a study on this subject. The study evaluates the effects of inert gas in reducing the risk associated with cargo tank fires and explosions in chemical tankers and oil tankers smaller than 20.000 DWT. They conducted an Official Security Assessment study for this assessment. Afterward, they made a cost-benefit analysis. As a result, they concluded that conventional inert gas systems (IGS) in 8.000-20.000 DWT oil tankers are cost-effective in terms of both safety and the environment. Simultaneously, it is concluded that IGS eliminates the vital risks that may arise from individual errors. In Sawada and Mitamoto [15], a study was conducted on the history of directly reduced iron and the market's expectations. They benefited from research, analysis, and statistical data collection methods. The data obtained are statistically evaluated and the production, demands, and environmentalism of the production method are examined based on countries and regions. Even in developed countries such as the USA, it is observed that the demand for reduced iron produced by an environmentally friendly production method as an alternative source is increasing. They also found that DRI shipments increased and continued to increase over the years.

For a fast reaction to occur in a metallization, the molecule must be smaller. In this way, as is known, it can react very quickly [16]. Tsutsumi et al. [17] suggested that the midrex process can be used to reduce energy consumption in DRI production. Besides, with reduced emissions, environmental $\mathrm{CO}_{2}$, and other types of emissions, the midrex process emits much less $\mathrm{CO}_{2}$ than other processes due to the gas nature. For this reason, Tsutsumi et al. [17] stated that the midrex process would also contribute significantly to coal emission reduction.

In [18], commercially available coals were characterized to determine their suitability as carbonaceous materials for 

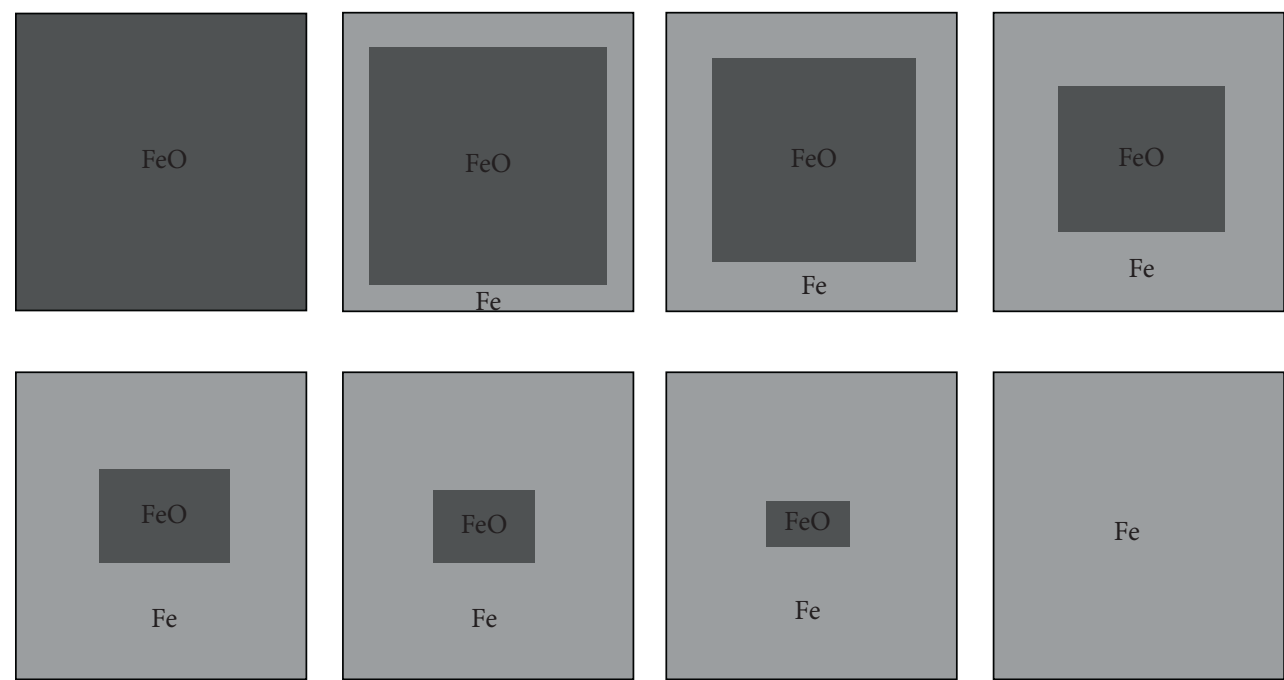

FIGURE 2: Schematic representation of the progressive reduction of iron oxides [8].

TABLE 2: Reaction chain showing reduction and carburization reactions.

\begin{tabular}{|c|c|c|c|}
\hline \multicolumn{4}{|c|}{ Reduction reactions } \\
\hline & 1 & $\mathrm{Fe}_{2} \mathrm{O}_{3}+3 \mathrm{CO} \leftrightarrow 2 \mathrm{Fe}+3 \mathrm{CO}_{2}$ & \\
\hline \multirow{4}{*}{1} & 2 & $3 \mathrm{Fe}_{2} \mathrm{O}_{3}+\mathrm{CO} \leftrightarrow 2 \mathrm{Fe}_{3} \mathrm{O}_{4}+\mathrm{CO}_{2}$ & Hematite $\left(\mathrm{Fe}_{2} \mathrm{O}_{3}\right)$ \\
\hline & 3 & $3 \mathrm{Fe}_{2} \mathrm{O}_{3}+\mathrm{H}_{2} \leftrightarrow 2 \mathrm{Fe}_{3} \mathrm{O}_{4}+\mathrm{H}_{2} \mathrm{O}$ & $69.9 \% \mathrm{Fe}$ \\
\hline & 4 & $\mathrm{Fe}_{2} \mathrm{O}_{3}+3 \mathrm{H}_{2} \leftrightarrow 2 \mathrm{Fe}+3 \mathrm{H}_{2} \mathrm{O}$ & $30.1 \% \mathrm{O}$ \\
\hline & 5 & $3 \mathrm{Fe}_{2} \mathrm{O}_{3}+\mathrm{C} \leftrightarrow 2 \mathrm{Fe}_{3} \mathrm{O}_{4}+\mathrm{CO}$ & \\
\hline \multirow{5}{*}{2} & 1 & $\mathrm{Fe}_{3} \mathrm{O}_{4}+\mathrm{C} \leftrightarrow 3 \mathrm{FeO}+\mathrm{CO}_{2}$ & \multirow{5}{*}{$\begin{array}{c}\text { Magnetite }\left(\mathrm{Fe}_{3} \mathrm{O}_{4}\right) \\
72.4 \% \mathrm{Fe} \\
27.6 \% \mathrm{O}\end{array}$} \\
\hline & 2 & $\mathrm{Fe}_{3} \mathrm{O}_{4}+\mathrm{CO} \leftrightarrow 3 \mathrm{Fe}+\mathrm{CO}_{2}$ & \\
\hline & 3 & $\mathrm{Fe}_{3} \mathrm{O}_{4}+\mathrm{H}_{2} \leftrightarrow 3 \mathrm{FeO}+\mathrm{H}_{2} \mathrm{O}$ & \\
\hline & 4 & $\mathrm{Fe}_{3} \mathrm{O}_{4}+4 \mathrm{CO} \leftrightarrow 3 \mathrm{Fe}+4 \mathrm{CO}_{2}$ & \\
\hline & 5 & $\mathrm{Fe}_{3} \mathrm{O}_{4}+4 \mathrm{H}_{2} \leftrightarrow 3 \mathrm{Fe}+4 \mathrm{H}_{2} \mathrm{O}$ & \\
\hline \multirow{3}{*}{3} & 1 & $\mathrm{FeO}+\mathrm{C} \leftrightarrow \mathrm{Fe}+\mathrm{CO}$ & \multirow{3}{*}{$\begin{array}{c}\text { Magnetite }\left(\mathrm{Fe}_{3} \mathrm{O}_{4}\right) \\
77.7 \% \mathrm{Fe} \\
22.3 \% \mathrm{O}\end{array}$} \\
\hline & 2 & $\mathrm{FeO}+\mathrm{CO} \leftrightarrow \mathrm{Fe}+\mathrm{CO}_{2}$ & \\
\hline & 3 & $\mathrm{FeO}+\mathrm{H}_{2} \leftrightarrow \mathrm{Fe}+\mathrm{H}_{2} \mathrm{O}$ & \\
\hline \multirow{5}{*}{4} & & Carburization reactions & \multirow{5}{*}{$\begin{array}{c}\text { Metallic iron } \\
100 \% \mathrm{Fe} \\
0 \% \mathrm{O}\end{array}$} \\
\hline & 1 & $3 \mathrm{Fe}+\mathrm{CH}_{4} \leftrightarrow \mathrm{Fe}_{3} \mathrm{C}+2 \mathrm{H}_{2}$ & \\
\hline & 2 & $3 \mathrm{Fe}+2 \mathrm{CO} \leftrightarrow \mathrm{Fe}_{3} \mathrm{C}+\mathrm{CO}_{2}$ & \\
\hline & 3 & $3 \mathrm{Fe}+\mathrm{CO}+\mathrm{H}_{2} \leftrightarrow \mathrm{Fe}_{3} \mathrm{C}+\mathrm{H}_{2} \mathrm{O}$ & \\
\hline & 4 & $\mathrm{Fe}+\mathrm{CO}+\mathrm{H}_{2} \leftrightarrow \mathrm{Fe}$ (Cfree) $+\mathrm{H}_{2} \mathrm{O}$ & \\
\hline
\end{tabular}

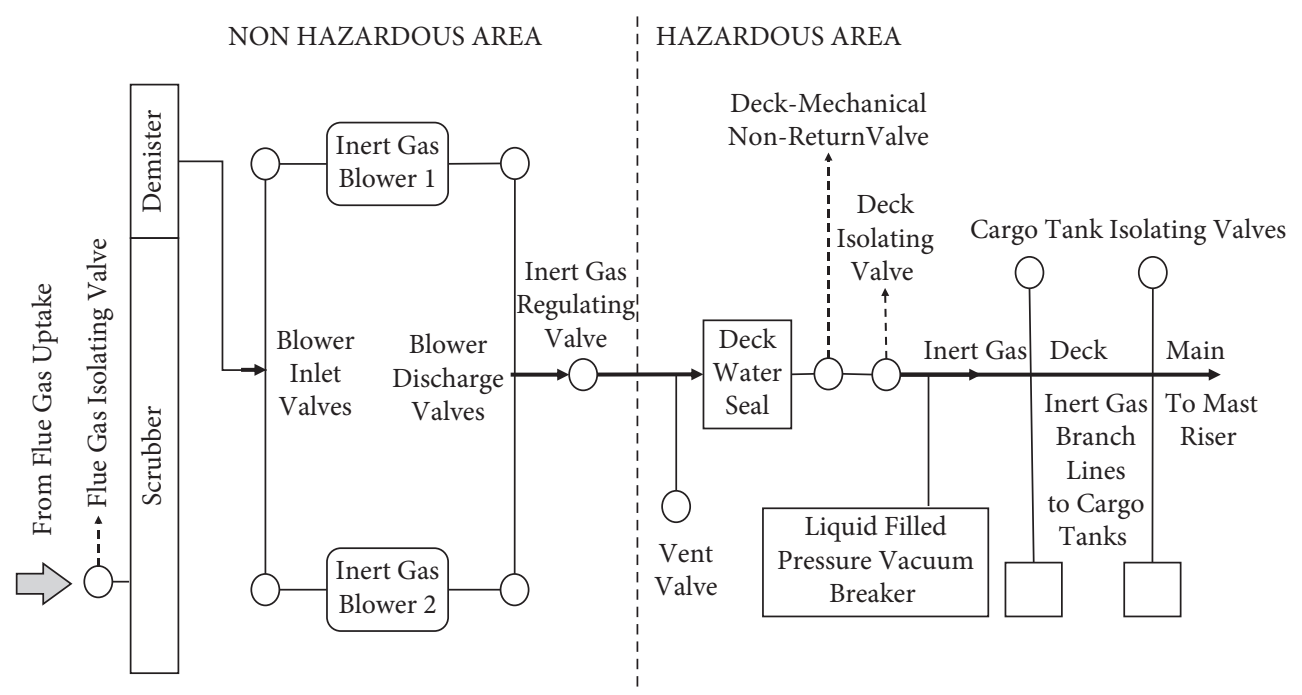

FIgURE 3: A typical inert gas system layout [10]. 
the production of DRI. Proximate and higher heating value analyses and FTIR (Fourier transform infrared spectrophotometry) and SEM-EDX (energy dispersive X-ray spectroscopy) characterization methods were used. As a result, they concluded that there are clay/sedimentary rocks that are not useful for the direct reduced iron making process, so samples available on the coal market should be thoroughly characterized before use.

Li et al. [19] performed a combined experiment and a DFT computational study to reveal new insights into the reoxidation of directly reduced iron (DRI) during the ball-mill operation. According to their studies, the re-oxidation of the iron powder takes place by diffusion from the nano surface into the interior, and after the iron is bonded with oxygen, the atoms on the iron surface become loose and the chance of deep iron atoms to come into contact with oxygen increases, as calculated by DFT. They concluded that the reduction time should be appropriately extended to reduce surface defects of new iron particles, that the semi-wet ballmill process and DRI are not suitable for processing, and that the ideal one should be selected from other wet ball mills. Safarian [20] applied an integrated duplex process method to examine the mass and energy balances to produce ferromanganese and directly reduced iron (DRI) with natural gas. He concluded that the production of ferromanganese and DRI with natural gas is feasible in terms of process chemistry in a FeMn reactor and causes $40 \%$ less CO2 emissions. Abd Elmomen [21] conducted a study to simulate and examine the kinetics of HDRI re-oxidation in still air at temperatures between 150 and $450^{\circ} \mathrm{C}$. Comparing the calculated and measured data, he explained that below $200^{\circ} \mathrm{C}$, no significant re-oxidation occurred and that in the relatively higher temperature range of 300 to $450^{\circ} \mathrm{C}$, the re-oxidation process was controlled by pore diffusion.

The most basic trends and types of changes in Bulk Cargoes/International Maritime Solid Bulk Cargoes Code (BC/IMSBC) regarding the shipment of a specific group of cargo, such as bulk cargoes, were discussed by LeśmianKordas and Bojanowska [22]. The changes in the content layout prove that standardized information on all kinds of dangerous goods (IMSBC A, B, and C groups) are advantageous. It aims to facilitate the use of the IMSBC Code in shipping operations. Maritime transport technology explains examples of detailed and expanded information on the technological shipping quality of solid bulk cargoes. Another study on solving DRI cargo's burning problem was conducted by Paswan and Mukherjee [4]. They did some experiments in the differential scanning calorimetry (DSC) lab to find the exact cause of DRI's burning. These experiments are labexp-1, labexp-2, labexp-3, labexp-4, and labexp-5 in which the purpose of these experiments is to know exactly the causes and conditions of combustion. As a result, they argue that the best solution is the method (passivization process/neutralization) applied to prevent rusting by cutting the contact of acid with or alkaline products and iron.

Djadjev [23] designed the research for shipowners and practitioners and students who want to review or expand their knowledge about this particular area of maritime transport as well as maritime transport. Djadjev [23] ensured that readers have a comprehensive understanding of the IMDG Code. The second part of the document also addresses the most common problems and hazards associated with the transportation of solid bulk cargoes (IMSBC Code) and the transportation of DRI cargoes. In general, it analyzes the process of transporting dangerous goods from the perspective of the carrier and therefore preparing a relevant manual for the transport of dangerous goods.

A study to measure the probability of human error in inert processes, which is one of the most critical processes in a crude oil tanker, was conducted by Akyuz [24]. In this context, the author used the cognitive reliability and error analysis method (CREAM), which is a risk-based methodology to evaluate the probability of human error, and reduced the risk during critical ship processes. Basically, crude oil tanker operations require a high level of safety and environmental protection compared to other merchant ship operations types. The research states that human performance should be monitored to improve deck operations and reduce disruptive errors.

The effect of DRI on the phosphorus removal reaction between the EAF and molten iron was investigated by Heo and Park [25]. They also discussed phosphorus behavior based on experimental results and thermodynamic studies. According to the results, they realized that the behavior of phosphorus, oxygen, and carbon is a function of reaction time at each stage of the reaction. They also clearly found that these three gases are dependent on the DRI mixing ratio. Sitov et al. [3] conducted a study to determine safe technological parameters in the process of transporting directly reduced iron by sea, depending on physicochemical properties. They used the mathematical formulation method to investigate the thermophysical models of spontaneous combustion and determined the spontaneous combustion process parameters based on kinetic determination methods. There are two kinetic parameters of spontaneous combustion for DRI cargo. These are known thermophysical properties and the height or diameter of the deposited layer. Finally, they found that these parameters have critical values. Also, while preparing a loading plan, they recommend paying attention to the principles of transport safety during the voyage for the permissible load height and temperature values in ship's cargo spaces according to the fire criteria. Another study relied on the statistics of ship accidents/incidents in ships transporting hazardous materials in the Turkish maritime sector, based on data from the Main Search and Rescue Coordination Center (MRCC) [1]. It conducted research to determine the causes of these accidents by using MRCC records between 11.11.2001 and 03.10.2016. They determined that the accidents with the broadest impact distances among maritime accidents occur because of fire and explosions. They found that this effect increased, especially in incidents involving dangerous chemicals. Mandova [26] evaluated whether the use of limited biomass resources is a strategic decision. In this study, using sophisticated techno-economic models, the researcher identified potential $\mathrm{CO} 2$ emissions. The researcher further defined the carbon prices required to 
increase its economic viability. Ultimately, she showed that bio-energy can reduce up to $40 \%$ in the field. $99.987 \%$ high purity iron production was examined by Li et al. [27]. In this method, the oxygen elements are reduced by using hydrogen from iron ore. In the oxygen reduction process, phosphorus is removed from iron using iron oxide $(\mathrm{FeO})$ simultaneously. The study shows that this method can produce high purity iron in a low cost and environmentally friendly manner. Salaheldine Darwish et al. [28] performed the hazard and operability technique in a specific DRI industry segment. They aimed to measure the results by monitoring layers of protection analysis (LOPA) and determined whether the independent protection layers in the system are sufficient. It was determined the result required by the safety integrity level (SIL) target. Finally, for risk assessment, fuzzy logic is used as an effective way to estimate the frequency and determine the SIL ratio by comparing it with that obtained from the LOPA study. Glushchenko [29] analyzed the potential and possible de-carbonization (carbon reduction) areas of steel production to reduce $\mathrm{CO}_{2}$ emissions and recommended policy measures to the government. He examined the structure of global carbon dioxide emissions, trends in $\mathrm{CO}_{2}$ emissions from the steel industry, and the environmental policies of the EU and China's environmental policies. They also characterized economic and technological factors that make the de-carbonization of the steel industry difficult. Kim [30] compared the carbon intensity of various de-carbonization technologies and potential terms for their commercial applications in his doctoral dissertation. As a result, the researcher identified economic policy tools to accelerate the steel industry's de-carbonization and analyzed the advantages and disadvantages of these economic policy tools. In another paper, the effects of loading cold briquetted iron and carbon (CBIC) into an electric furnace on steel production operating parameters were investigated by Paknahad et al. [31]. Ko $\alpha \beta$ [32] analyzed a naval court case that emerged during the delivery of damaged DRI-loaded freight. Although the claim is based on a fake bill of lading set, these parameters caused the vessel to be arrested and auctioned, as any subsequent financial security could not be provided/secured by the shipowners or the P\&I Club.

Dam [33] applied The UN Test N.5 to evaluate the spontaneous heating properties of loads and materials that show a clear trend in marine fire and explosion events. He has reached the outcome that the external factors might cause spontaneous heating and emit flammable gases which could seriously affect the safety of crew and ships. Moreover, these external factors are moisture content, storage procedure, air movements, and internal and external pressures on the load. As a result, it shows that regardless of the chemical composition of the reactive material, self-heating and flammable gas emissions have a typical pattern when reacting with any oxygen source. An EAF energy efficiency model based on the closed mass and energy balance of the EAF melting process was developed in [34]. Moreover, they demonstrated the importance of efficient foam slag processing in EAF steel-making, from the energy conversion efficiency of electric arc energy to steel temperature sensitivity. Elango [35] conducted an analysis study to examine and improve the life cycle of DRI production based on coal in India. In the study, the researcher developed a framework for evaluating based on literature review and data collection. It is concluded that the expansion of production capacity, especially in areas closer to the mining zones, would enable it to increase mine productivity, reduce the burden on shipping and production, and improve the output and operating conditions of the DRI facility. In another paper, an analysis study to use freshwater scrubbers instead of seawater due to the corrosive properties of the inert gas system seawater scrubbers was conducted by Siswantoro et al. [36]. In their research, they have worked on 85.000 DWT crude oil tankers. Seawater scrubber systems are ineffective due to their abrasive properties. Therefore, they used formulation and calculation methods to determine the effect levels of freshwater systems with lower corrosive effects. They concluded that the modification is technically feasible but also has a financial cost.

As can be seen from the literature review, many studies are completed on the structure, production, production stages of the DRI cargo, the properties of the systems used in its production, the reducers used, its costs, and environmental hazards. However, it is concluded that there is not enough research or study done on the transportation of DRI cargo by sea, dangers, and development of transportation methods against these dangers. This study is carried out to fill this gap and to create alternative methods for safely transporting DRI cargo by sea.

\section{Intuitionistic Fuzzy TOPSIS Method}

In this paper, an extended IF-TOPSIS method is used as in [37]. The steps of the IF-TOPSIS are given in a stepwise manner below:

(1) Intuitionistic fuzzy decision matrix $D=\left(\widetilde{a}_{i j}\right)_{m \times n}$ is constructed in the form of intuitionistic fuzzy numbers $\widetilde{a}_{i j}=\left(\mu_{i j}, v_{i j}\right)(i=1,2, \ldots, m ; j=1,2, \ldots$, $n$ ) for $m$ alternatives and $n$ criteria [38].

$$
D=\left(\tilde{a}_{i j}\right)_{m \times n}=A_{2} \quad \begin{array}{cccc}
C_{1} & C_{2} & \ldots & C_{n} \\
\vdots & A_{m}
\end{array}\left(\begin{array}{cccc}
\tilde{a}_{11}^{*} & \tilde{a}_{12}^{*} & \ldots & \tilde{a}_{1 n}^{*} \\
\tilde{a}_{21}^{*} & \tilde{a}_{22}^{*} & \ldots & \tilde{a}_{2 n}^{*} \\
\vdots & \vdots & \ddots & \vdots \\
\tilde{a}_{m 1}^{*} & \tilde{a}_{m 2}^{*} & \ldots & \tilde{a}_{m n}^{*}
\end{array}\right) .
$$

(2) Positive ideal solution (PIS) is found for each criterion based on intuitionistic fuzzy sets $\tilde{a}^{+}=\left(\tilde{a}_{1}^{+}, \tilde{a}_{2}^{+}, \ldots, \tilde{a}_{n}^{+}\right)$. Equation (2) is used to find the PIS [39]. 


$$
\tilde{a}_{j}^{+}= \begin{cases}\left(\max _{1 \leq i \leq m}\left\{\mu_{i j}\right\}, \min _{1 \leq i \leq m}\left\{v_{i j}\right\}\right)=\left(\mu_{j}^{+}, v_{j}^{+}\right), & \text {if } C_{j} \in C^{+}, \\ \left(\min _{1 \leq i \leq m}\left\{\mu_{i j}\right\}, \max _{1 \leq i \leq m}\left\{v_{i j}\right\}\right)=\left(\mu_{j}^{+}, v_{j}^{+}\right), & \text {if } C_{j} \in C^{-},\end{cases}
$$

where $C^{+}$and $C^{-}$are the sets of benefit and cost criteria, respectively, and $1 \leq j \leq n$. $\tilde{a}^{-}=\left(\tilde{a}_{1}^{-}, \tilde{a}_{2}^{+}, \ldots, \tilde{a}_{n}^{-}\right)$. Equation (3) is used to find the NIS [40].

(3) Negative ideal solution (NIS) is found for each criterion based on intuitionistic fuzzy sets

$$
\tilde{a}_{j}^{-}= \begin{cases}\left(\min _{1 \leq i \leq m}\left\{\mu_{i j}\right\}, \max _{1 \leq i \leq m}\left\{v_{i j}\right\}\right)=\left(\mu_{j}^{-}, v_{j}^{-}\right), & \text {if } C_{j} \in C^{+}, \\ \left(\max _{1 \leq i \leq m}\left\{\mu_{i j}\right\}, \min _{1 \leq i \leq m}\left(v_{i j}\right)\right)=\left(\mu_{j}^{-}, v_{j}^{-}\right), & \text {if } C_{j} \in C^{-},\end{cases}
$$

where $C^{+}$and $C^{-}$are the sets of benefit and cost criteria, respectively, and $1 \leq j \leq n$.
(4) Positive intuitionistic fuzzy distance matrix $D^{+}$is calculated by using the following equation:

$$
\begin{aligned}
& C_{1} \quad C_{2} \quad \ldots \quad C_{n}
\end{aligned}
$$

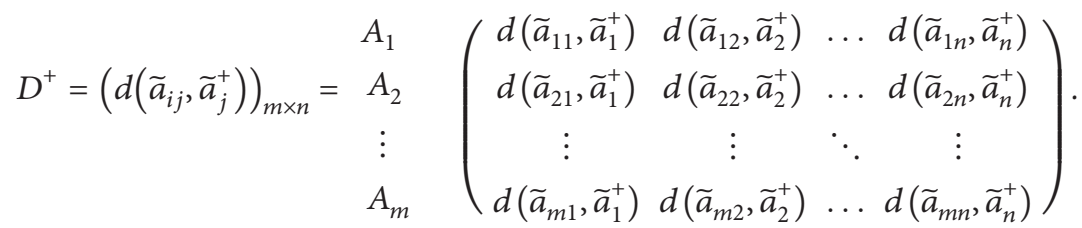

The distance measure between two intuitionistic fuzzy numbers $\alpha=\left(\mu_{\alpha}, v_{\alpha}\right)$ and $\beta=\left(\mu_{\beta}, v_{\beta}\right)$ is found in the following equation:

$d(\alpha, \beta)=\sqrt{\frac{\left[\mu_{\alpha}\left(1+(2 / 3) \pi_{\alpha}\left(1+\pi_{\alpha}\right)\right)-\mu_{\beta}\left(1+(2 / 3) \pi_{\beta}\left(1+\pi_{\beta}\right)\right)\right]^{2}+\left[v_{\alpha}\left(1+(2 / 3) \pi_{\alpha}\left(1+\pi_{\alpha}\right)\right)-v_{\beta}\left(1+(2 / 3) \pi_{\beta}\left(1+\pi_{\beta}\right)\right)\right]^{2}}{2}}$

According to Boran and Akay [41], $\mu_{\alpha}$ and $\nu_{\alpha}$ can be equal to any value in $\left[\mu_{\alpha}, \mu_{\alpha}+\pi_{\alpha}\right]$ and $\left[\nu_{\alpha}, \nu_{\alpha}+\pi_{\alpha}\right]$, respectively.
(5) Negative intuitionistic fuzzy distance matrix $D^{-}$is calculated by using the following equation:

$$
\begin{aligned}
& C_{1} \quad C_{2} \quad \ldots \quad C_{n}
\end{aligned}
$$

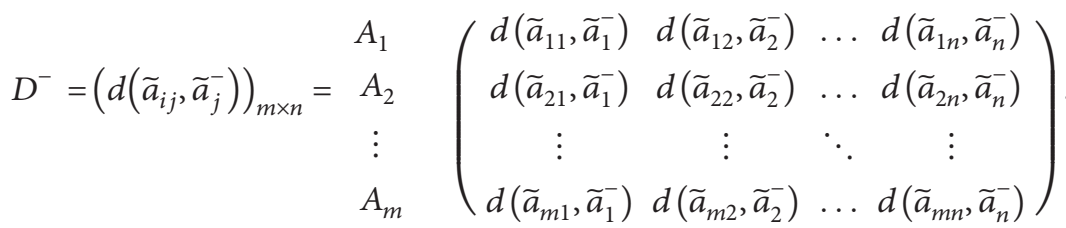

(6) Composite intuitionistic fuzzy distance matrix $D^{*}=$ $D^{-}-D^{+}$is calculated by using the following equation: 


$$
\begin{aligned}
& \begin{array}{cccc}
C_{1} & C_{2} & \cdots & C_{n}
\end{array}
\end{aligned}
$$

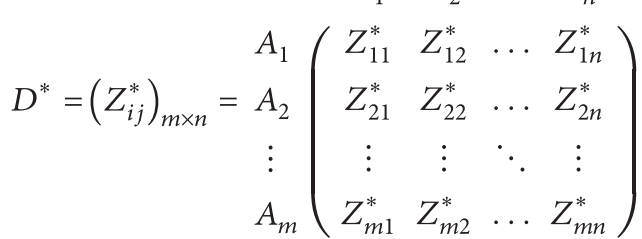

$$
\begin{aligned}
& \begin{array}{llll}
C_{1} & C_{2} & \cdots & C_{n}
\end{array}
\end{aligned}
$$

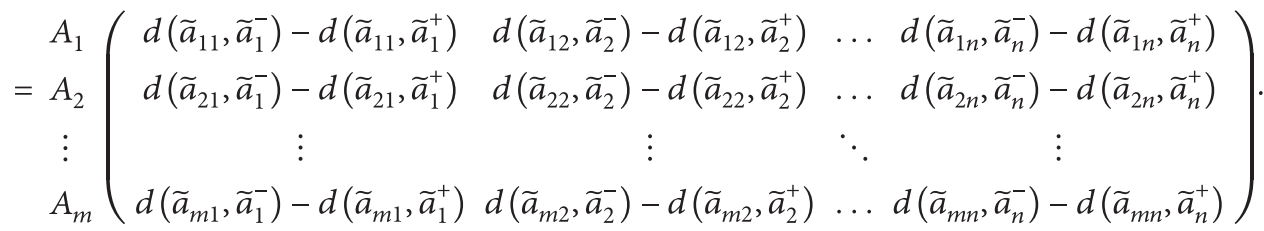

(7) Optimal weights for each criterion are computed by using the following equation:

$$
w_{j}^{*}=\frac{\sum_{i=1}^{m} \sum_{k=1}^{m}\left|Z_{i j}-Z_{k j}\right|}{\sum_{j=1}^{n} \sum_{i=1}^{m} \sum_{k=1}^{m}\left|Z_{i j}-Z_{k j}\right|},
$$

where $w_{j}^{*}$ is the optimal weight of the criterion $C_{j}$.

(8) Weighted intuitionistic fuzzy distance measures for each alternative $\widetilde{D}_{i}$ are calculated as follows:

$$
\widetilde{D}_{i}=\sum_{j=1}^{n} w_{j}^{*} Z_{i j}^{*}, i=1,2, \ldots, m .
$$

(9) Alternatives are ranked based on $\widetilde{D}_{i}$.

\section{Particulars of Criteria and Alternatives}

If the DRI gets spontaneous heat and comes into contact with oxygen or water, because of the oxidation reaction, it might create massive risks such as ignition, explosion, and fire. Thus, to transport DRI cargoes by sea, which are classified as dangerous cargo, the inert process should be done to the ship's holds. Five alternative inert gas systems and five criteria are determined to choose this inert system and evaluate the best option based on these criteria.

5.1. Criteria. Based on our research and expert consultations, there are five significant criteria for this problem. The titles and their definitions are given below.

5.1.1. Criterion 1: Installation Cost of the System. If the bulk/ dry cargo shipowners or operators make long-term plans to regularly transport DRI cargo that is classified as dangerous cargo or cargo with similar hazards, they should choose any of the inert gas systems [2]. Inert gas systems are systems used in ships carrying dangerous liquid cargo. It is not the preferred system in bulk/dry cargo ships. Therefore, equipping these systems on bulk/dry cargo ships means an unaccounted cost. Installation costs of the system may increase or decrease depending on the size and tonnage of the ship. Since a new system is equipped on the ship, new pipelines will be included in the installation costs. Also, if the ship to be equipped with the inert gas system does not fit to a new-building ship but a ship already in operation, then the labour cost will be included in the system's installation cost. The supply of inert gas needed from external sources (port facilities), albeit one-time, can be provided for specific fees.

5.1.2. Criterion 2: Safety Factor. Due to the dangers of the DRI cargo, the safety factor is of paramount importance. It is challenging to provide full gas tightness on hatch covers in bulk/dry cargo ships. For this reason, it is highly probable that the inert gas concentration in the warehouse decreases, and the oxygen ratio increases accordingly during the transport of the DRI cargo. The DRI cargo will create dangers such as flammability/explosion/ combustion due to the decrease in the cargo hold's inert gas rate for any reason during the period between the loading of the cargo and its discharge [2]. As a result, serious consequences may be encountered that may result in loss of life and loss of the ship as well as material damage. These dangers show the importance of the system in terms of the safety factor. It is important to keep the inert gas concentration in the cargo hold or space at the required rates to avoid dangerous situations. Therefore, the system must be capable of minimizing or eliminating these dangers.

5.1.3. Criterion 3: Operating Costs of the System. Inert gas systems are not mostly preferred in bulk/dry cargo ships. Therefore, officers and personnel working on such ships are not sufficiently trained and experienced in inert gas. It is recommended that both deck and engine personnel receive applied training in a continuous and coordinated manner to master the inert gas system's technical features [10]. Private training institutions outside the company usually provide these pieces of training. Since the officers and personnel's inert gas system training to be equipped on the ship is a specific training, these training expenses are generally covered by the companies. These training expenditures are 
reflected in the company as an expense for the operation of the system. Inert gas systems need energy. For example, fuel consumption is required to obtain flue gas. There is no extra cost for inert gas systems during the voyage. However, when the machine does not work, extra fuel consumption is made for inert gas systems [42]. Besides, other inert gas and nitrogen systems also require electrical energy. Each system means extra energy consumption and fuel consumption [42].

5.1.4. Criterion 4: Maintenance Cost of the System. To use the systems effectively, maintenance works are of great importance. Inert gas systems, like other systems, are systems with their own technical details and structures. Deck and engine personnel should carry out the necessary maintenance work and operations of inert gas systems in a coordinated manner and at regular intervals [43]. As it is known, maintenance operations are operations that require spare parts and technical service when necessary. Both spare parts supply and technical service support create an extra expense for the business. If the ship is outside the port country, often both technical service costs and spare parts supply cause greater costs. The company or the business that will make an inert gas system preference should also consider the spare parts supply and prices of the related systems and the technical service networks.

5.1.5. Criterion 5: Waste of Time. As it is known, loss of time in the commercial field always causes financial losses. The loss of time is equally important when it comes to the maritime sector and ships, where large-scale trade and transportation are carried out. The process of pumping inert gas into cargo holds is a process performed after the holds' loading processes are completed. In other words, inert operations may cause the ship to stay in the port longer and, consequently, lose time. Also, the port authorities can determine whether the ships loaded with dangerous goods in their ports are safe in terms of the existing dangers of the cargo and approve their departure. Moreover, they have control and supervision powers for inert gas systems. As a result of the control and inspection, if it is concluded that the current system is adequate and effective following international conventions such as Safety of Life at Sea (SOLAS), the International Convention for the Prevention of Pollution from Ships (MARPOL), STCW, and Maritime Labour Convention (MLC), they may allow the ship to leave the port before the inert process is completed. Otherwise, if any deficiency is detected, the ships are not allowed to leave the port. Besides, it is not allowed to start the voyage without completing the inert processes on the ship and monitoring the warehouse gas measurement values for a certain period $[44,45]$. These situations cause loss of time and financial losses for the ships and their operations. Efficiency, capacities of inert gas systems, and being prepared for possible controls and inspections are of great importance in terms of time losses.

5.2. Alternatives. There are five alternatives of inert gas systems for the transportation of DRI.
5.2.1. Alternative 1: Uptake Gas from the Ship's Boilers. The systems that produce inert gas from the flue gas from the main and auxiliary boilers of the ship provide load safety against dangers such as flashing and explosion in oil tankers and chemical tankers. Also, they are systems that provide positive pressure to the tanks and produce inert gas from the flue gas so that the cargo tanks are not damaged due to pressure or vacuum during loading and discharging. There are high-capacity boilers on ships (tankers) that can produce inert gas using flue gas. In these boilers, typical flue gas is obtained by burning a fuel-air mixture. Then, an inert gas is obtained by cooling, cleaning, and drying processes in the inert gas system. The inert gas obtained can be fed to the tanks through the circuits equipped with the deck, and the oxygen concentration in the tank can be reduced to the desired levels [43]. These systems can also be equipped for bulk/dry cargo ships carrying dangerous goods and needing inert gas and can be used for the same purposes [5].

\subsubsection{Alternative 2: Independent Inert Gas Generator.} The operation of the ship's boilers is not economical as in voyage. Therefore, independent inert gas generators are generators that are used as an auxiliary element in case ship boilers are not desired to operate. These generators are independent generators that do not use the flue gas from the boilers. The purpose of use, operating system, and technical features are the same as the systems producing inert gas with gas from ship boilers. This system is used to fill cargo tanks with inert gas when the ship is fully loaded. When the ship is fully loaded, the need for inert gas is more diminutive. Simultaneously, this inert gas generator is sufficient to provide inert gas during evacuation and cleaning [5, 42].

5.2.3. Alternative 3: Nitrogen Generator. The nitrogen generator is partially installed in the engine room, and the rest is equipped on the deck like other systems. Its capacity is based on the percentage of $\mathrm{O}$ in $\mathrm{N}$ calculated at an ambient temperature of $20 \mathrm{C}, 80 \%$ relative humidity, and atmospheric pressure. Hollow fiber membranes are used in the system to separate the air into nitrogen and oxygen. The separation principle is based on the selective permeability of nitrogen and oxygen. The system consists of four main stages: air supply, pretreatment of air, separation of product gas, and control of the system [42]. Nitrogen generators are also systems used to keep the cargo tank's oxygen level or warehouse at desired levels [43].

\subsubsection{Alternative 4: Inert Gas or Nitrogen Supplied from} External Sources. In port facilities where dangerous cargo is handled, the inert gas requirement can be met from inert gas or nitrogen systems provided by the port authority or loaders. While these systems are used by big tankers and chemical tankers in emergencies, they are used in cases of dangerous cargo transportation in bulk/dry cargo ships. External pipelines are equipped by the port facility to which the cargo will be loaded, and inert gas or nitrogen is sent to 
spaces/warehouses with hazardous cargoes to obtain desired oxygen and other gas concentrations [43].

5.2.5. Alternative 5: Fixed Nitrogen Tubes. Fixed nitrogen tubes consist of fixed nitrogen tubes used in tankers to provide positive pressure to tanks in emergencies and circuits that distribute nitrogen inside the tubes to the tanks [43]. Fixed nitrogen tubes can also be equipped to pump nitrogen into holds on bulk/dry cargo ships carrying dangerous cargo. Self-sustainable autonomous gas generator turbine (gas turbine) and "self-sustainable autonomous diesel engine" [42] systems are also other systems used in inert gas production. However, since their use in ships is not common, they are not considered as an alternative in this study [5].

\section{Application}

In this study, the inert gas system selection problem is investigated using the IF-TOPSIS method which was proposed by Shen et al. [37]. The authors discuss and demonstrate this method's superiority by comparing other research in the literature based on several parameters and considerations. The authors also declare that this method is verified and overcomes the drawbacks of the previous techniques. In their study, 18 distance measures are compared and a methodological comparison between the intuitionistic fuzzy TOPSIS method of Shen et al. and the other intuitionistic fuzzy TOPSIS methods is conducted. The structure of the IFTOPSIS method is provided in Figure 4. There are five criteria and five alternatives for this problem as mentioned in Section 5. The criteria are $\mathrm{C} 1$-installation cost of the system, C2-safety factor, C3-operating costs of the system, C4-maintenance cost of the system, and C5-waste of time. The alternatives are A1-uptake gas from the ship's boilers, A2-independent inert gas generator, A3-nitrogen generator, A4-inert gas or nitrogen supplied from external sources, and A5-fixed nitrogen tubes. We have made expert consultations to obtain the data. In the process of determining alternatives and criteria, it was worked with a group of experts in the field. Among the 7 alternatives determined in line with the opinions of the expert group, 5 inert gas systems, for which the expert group gave the most appropriate opinion, were selected as alternatives. In addition, among the 8 criteria determined by the expert group, the 5 most important criteria by the experts were selected for our study. This is an experienced expert group and their opinions are aggregated as a decision matrix. The experts evaluated the alternatives by considering each criterion. Based on our previous experiences, decision makers might have some doubts and hesitation about their evaluations. Therefore, we use intuitionistic fuzzy sets where $\mu_{\alpha} \in[0,1], v_{\alpha} \in[0,1], \mu_{\alpha}+v_{\alpha} \leq 1$ and $\pi_{\alpha}=1-\mu_{\alpha}+v_{\alpha}$ to cover their vagueness, ambiguity, and abstinence because of their decisions.

The decision-making process for the selection of inert gas system problem is completed by step-by-step manner.

Step 1. Intuitionistic fuzzy numbers $\tilde{a}_{i j}=\left(\mu_{i j}, v_{i j}\right)$ $(i=1, \ldots, 5$; and $j=1, \ldots, 5)$ are used to set the intuitionistic fuzzy decision matrix $D=\tilde{a}(i j)_{5 \times 5}$ as given below:

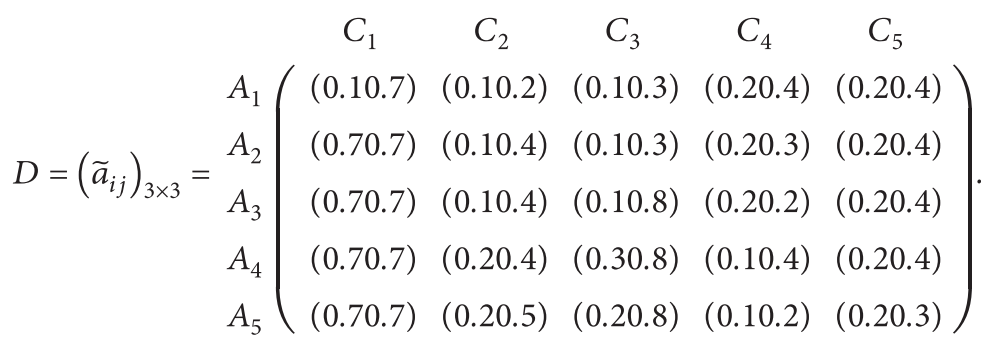

Step 2. Positive ideal solution is identified based on intuitionistic fuzzy sets, $\widetilde{a}^{+}=\left(\widetilde{a}_{1}^{+}, \widetilde{a}_{2}^{+}, \ldots, \widetilde{a}_{n}^{+}\right)$. There are five criteria, and $C 1, C 3, C 4$, and $C 5$ are the cost criteria, and $C 2$ is the benefit criterion. We can get the positive ideal solutions from the intuitionistic fuzzy evaluation matrix by using equation (2). Positive ideal solution is $\tilde{a}_{1}^{+}=(0.7,0.7), \quad \tilde{a}_{2}^{+}=(0.2,0.5), \quad \tilde{a}_{3}^{+}=(0.3,0.8)$, $\tilde{a}_{4}^{+}=(0.1,0.2)$, and $\widetilde{a}_{5}^{+}=(0.2,0.4) . \widetilde{a}^{+}=((0.7,0.7)$, $(0.2,0.5),(0.3,0.8),(0.1,0.2),(0.2,0.4))$.
Step 3. Negative ideal solution is identified based on intuitionistic fuzzy sets, $\widetilde{a}^{-}=\left(\widetilde{a}_{1}^{-}, \widetilde{a}_{2}^{-}, \ldots, \widetilde{a}_{n}^{-}\right)$. We can get the negative ideal solutions from the intuitionistic fuzzy evaluation matrix by using equation (3). Negative ideal solution is $\tilde{a}_{1}^{-}=(0.1,0.7), \quad \tilde{a}_{2}^{-}=(0.1,0.2)$, $\widetilde{a}_{3}^{-}=(0.1,0.3), \widetilde{a}_{4}^{-}=(0.2,0.4)$, and $\widetilde{a}_{5}^{-}=(0.2,0.2) \cdot \widetilde{a}^{-}=$ $((0.1,0.7),(0.1,0.2),(0.1,0.3),(0.2,0.4),(0.2,0.2))$.

Step 4. Positive intuitionistic fuzzy distance matrix $D^{+}$ is calculated by implementing equation (4). 


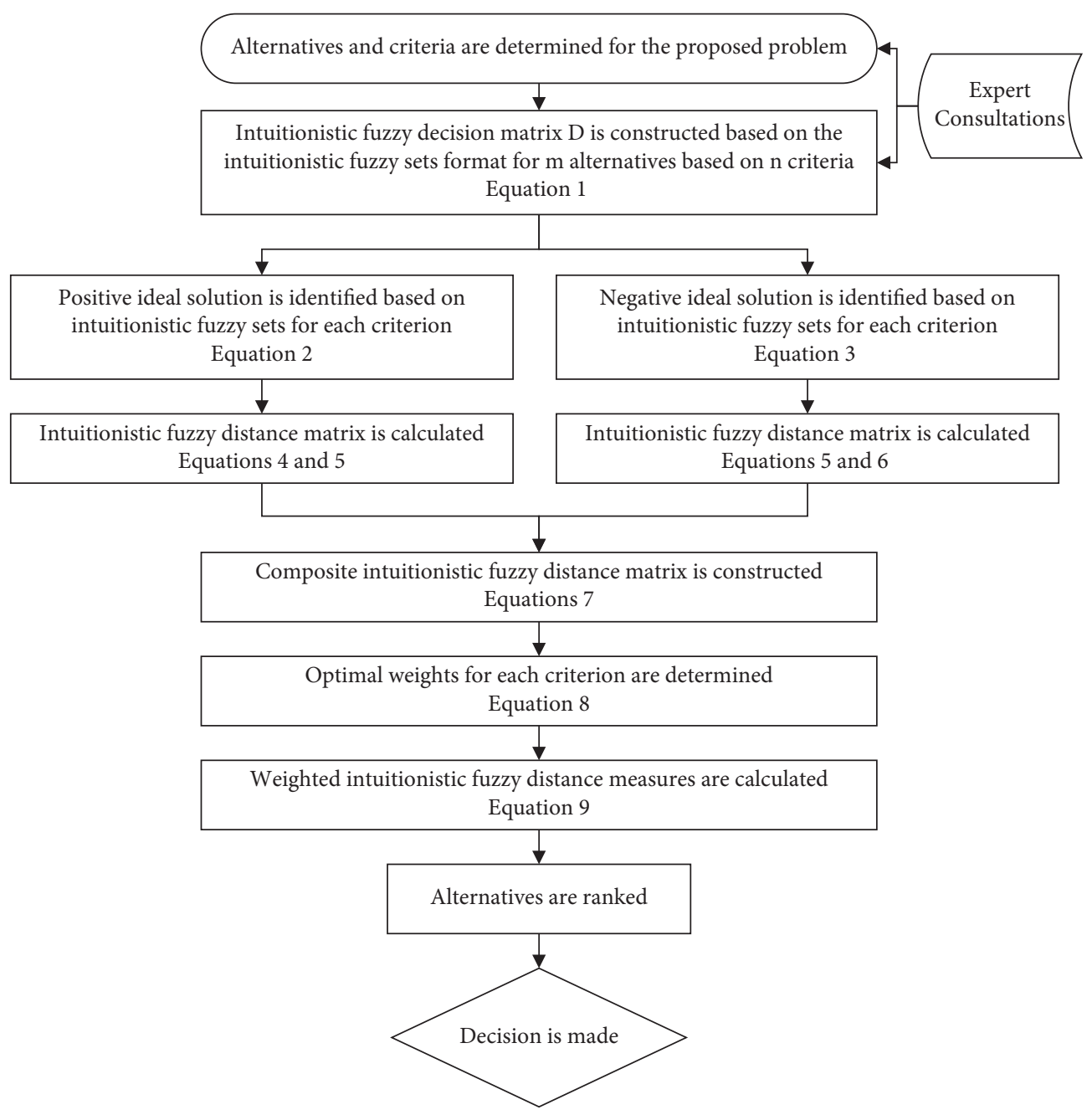

FIGURE 4: The structure of the IF-TOPSIS method.

$$
\begin{aligned}
& \begin{array}{llllll}
C_{1} & C_{2} & C_{3} & C_{4} & C_{5}
\end{array} \\
& D^{+}=\left(d\left(\tilde{a}_{i j}, \tilde{a}_{j}^{+}\right)\right)_{5 \times 5}=\begin{array}{c}
A_{1} \\
A_{2} \\
A_{3} \\
A_{4} \\
A_{5}
\end{array}\left(\begin{array}{lllll}
0.4554 & 0.2400 & 0.5229 & 0.1834 & 0.0000 \\
0.0000 & 0.1073 & 0.5229 & 0.1160 & 0.0000 \\
0.00000 & 0.1073 & 0.1942 & 0.0820 & 0.0000 \\
& 0.0759 & 0.0000 & 0.1640 & 0.0000 \\
& 0.0000 & 0.0971 & 0.0000 & 0.0759
\end{array}\right) .
\end{aligned}
$$

Step 5. Negative intuitionistic fuzzy distance matrix $D^{-}$

is calculated by implementing equation (6).

$$
\begin{aligned}
& \begin{array}{ccccc}
C_{1} & C_{2} & C_{3} & C_{4} & C_{5}
\end{array} \\
& \left.D^{-}=\left(d\left(\tilde{a}_{i j}, \tilde{a}_{j}^{+}\right)\right)_{5 \times 5}=\begin{array}{c}
A_{1} \\
A_{2} \\
A_{3}
\end{array} A_{4} \begin{array}{cccccc}
0.0000 & 0.0000 & 0.0000 & 0.0000 & 0.0759 \\
& 0.4554 & 0.1518 & 0.0000 & 0.0820 & 0.0759 \\
& A_{5} & 0.1518 & 0.4855 & 0.1640 & 0.0759 \\
0.4554 & 0.2400 & 0.4952 & 0.1834 & 0.0000
\end{array}\right) .
\end{aligned}
$$


Step 6. Composite intuitionistic fuzzy distance matrix $D^{*}$ is computed by using $D^{+}$and $D^{-}$(equation (7)):

$$
\begin{aligned}
& \begin{array}{lllll}
C_{1} & C_{2} & C_{3} & C_{4} & C_{5}
\end{array}
\end{aligned}
$$

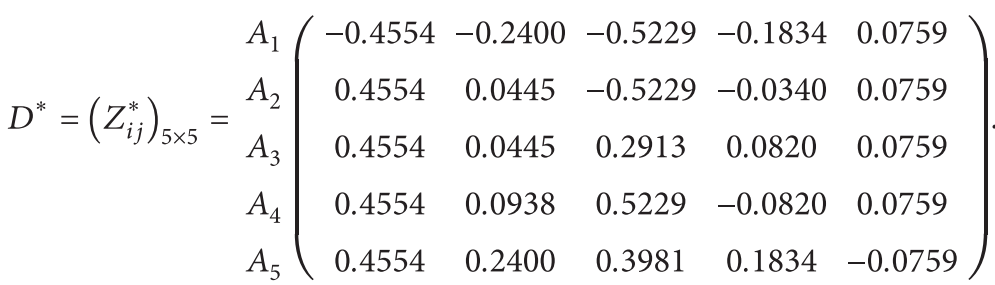

Step 7. Optimal weight for each criterion is determined by employing equation (7). The optimal weights for each criterion are calculated as follows.

$$
\begin{aligned}
& \sum_{i=1}^{5} \sum_{k=1}^{5}\left|Z_{i 1}^{*}-Z_{k 1}^{*}\right|=7.2860 \\
& \sum_{i=1}^{5} \sum_{k=1}^{5}\left|Z_{i 2}^{*}-Z_{k 2}^{*}\right|=4.0374 \\
& \sum_{i=1}^{5} \sum_{k=1}^{5}\left|Z_{i 3}^{*}-Z_{k 3}^{*}\right|=12.0512 \\
& \sum_{i=1}^{5} \sum_{k=1}^{5}\left|Z_{i 4}^{*}-Z_{k 4}^{*}\right|=3.5907 \\
& \sum_{i=1}^{5} \sum_{k=1}^{5}\left|Z_{i 5}^{*}-Z_{k 5}^{*}\right|=1.2143
\end{aligned}
$$

We can now find the optimal weights by a normalization process as mentioned in equation (9).

$$
\begin{aligned}
& w_{1}^{*}=\frac{7.2860}{28.1799}=0.2585, \\
& w_{2}^{*}=\frac{4.0374}{28.1799}=0.1432, \\
& w_{3}^{*}=\frac{12.0512}{28.1799}=0.4276, \\
& w_{4}^{*}=\frac{3.5907}{28.1799}=0.1274, \\
& w_{5}^{*}=\frac{1.2143}{28.1799}=0.0430 .
\end{aligned}
$$

Weighted intuitionistic fuzzy distance values for each alternative $D_{i}$ by using equation (9) are given below:

$$
\begin{aligned}
& \widetilde{D}_{1}=\sum_{j=1}^{5} w_{j}^{*} Z_{1 j}^{*}=-0.3959, \\
& \widetilde{D}_{2}=\sum_{j=1}^{5} w_{j}^{*} Z_{2 j}^{*}=-0.1006, \\
& \widetilde{D}_{3}=\sum_{j=1}^{5} w_{j}^{*} Z_{3 j}^{*}=0.26242, \\
& \widetilde{D}_{4}=\sum_{j=1}^{5} w_{j}^{*} Z_{4 j}^{*}=0.34764, \\
& \widetilde{D}_{5}=\sum_{j=1}^{5} w_{j}^{*} Z_{5 j}^{*}=0.34246 .
\end{aligned}
$$

Step 8. The alternatives are ranked based on the results of weighted intuitionistic fuzzy distances for each alternative $D_{i}$. According to results, $\widetilde{D}_{4}>\widetilde{D}_{5}>\widetilde{D}_{3}>\widetilde{D}_{2}>\widetilde{D}_{1}$. The most prior alternative is found as $\widetilde{D}_{4}$.

6.1. Analysis of Results. A sensitivity analysis is conducted based on the study of Celik and Akyuz [46] as in Table 3. We generated six cases to check the changes of the alternative rankings. For this scenario, we find that if each criterion takes the lowest value $(0.1,0.1)$, the rankings change in only Case 4 and Case 6. Rest of them remain the same.

As it can be seen from the literature review, while many studies have been conducted on the production and production stages of DRI and other areas of use of inert gas, no studies have been conducted on the safe transportation of this cargo by ships. This study eliminates the deficiency in maritime transport and can be a reference for future studies. The limited number of alternatives to inert gas systems is a limitation of this study. In general, dry/bulk cargo ships do not carry dangerous goods like DRI continuously and regularly. For this reason, shipowners do not prefer to equip such ships with inert gas systems. This is the other limitation of this study. 
TABLE 3: Changes of the results based on the different simulations.

\begin{tabular}{llcccc}
\hline Cases & & A1 & A2 & A3 & A4 \\
\hline Case 1 & Current & -0.39587 & -0.10059 & 0.262419 & 0.347641 \\
Case 2 & C1 lowest, all current & -0.37512 & -0.29447 & 0.195132 & 0.310071 \\
Case 3 & C2 lowest, all current & -0.43273 & -0.38673 & 0.249235 & 0.369472 \\
Case 4 & C3 lowest, all current & -0.30091 & 0.214994 & 0.240819 & 0.216651 \\
Case 5 & C4 lowest, all current & -0.42689 & -0.11032 & 0.288763 & 0.410386 \\
Case 6 & C5 lowest, all current & -0.41711 & -0.10854 & 0.270819 & 0.303078 \\
\hline
\end{tabular}

The study's main purpose is to use the IF-TOPSIS multicriteria decision-making method to select the most suitable inert system for the safe transport of dangerous DRI cargo via ships and compare the results obtained. The results indicate the rankings as inert gas or nitrogen supplied from external sources $\left(1^{\text {st }}\right)$, fixed nitrogen tubes $\left(2^{\text {nd }}\right)$, nitrogen generator $\left(3^{\text {rd }}\right)$, independent inert gas generator $\left(4^{\text {th }}\right)$, and uptake gas from ship boilers $\left(5^{\text {th }}\right)$, respectively.

6.2. Discussion. DRI cargo is a dangerous cargo transported by bulk/dry cargo ships. In the process of transporting by ships, it must be transported by inerting to cargo holds against flammability, explosion, and fire hazards. Inert gas systems are the systems used in ships carrying dangerous liquid cargo (chemical or petroleum products). It is not preferred to equip bulk/dry cargo ships with inert gas systems during the ship construction phase. Therefore, when it comes to transporting cargoes that require inerting, such as DRI cargoes, inert gas or nitrogen supplied from external sources is generally preferred. Although inert gas or nitrogen supplied from external sources is costly and insufficient for the shipowner, they may not choose to equip their ships with fixed inert gas or nitrogen systems if they do not always carry dangerous cargoes. If the vessel does not have a built in inert gas generator, it might help the owner or manager of the vessel to prevent making more expenses for the company, but it also increases the risk level of the vessel during the voyage significantly. Therefore, these voyages are kept as limited to short distances and highly discouraged to the longer voyage periods. Since dangerous cargoes such as DRI are generally recommended to be transported during short travel times, the safety factor can be ignored considering that they will not pose a problem in terms of safety.

Besides, inert gas or nitrogen supplied from external sources can be preferred at a higher rate because they do not create maintenance costs and are more advantageous than other systems in terms of loss of time. If an investor intends to carry loads that require inerting, such as DRI cargo, continuously, they may prefer other fixed inert gas and nitrogen systems in terms of cost. While the safety factor and loss of time are almost the same for each system, the fixed nitrogen tube system is more advantageous than the others in terms of operating cost and maintenance costs. Therefore, the fixed nitrogen tube system can be preferred at a higher rate. Systems that generate inert gas for ships do not have many types today. The study's disadvantage is that equipping inert gas systems on bulk/dry cargo ships is not preferred by investors. Therefore, existing alternatives were compared in terms of installation cost, safety factor, loss of time, operating cost, and maintenance cost.
6.3. Future Directions. This study will guide shipowners and investors who are considering short-term or long-term transportation of dangerous goods such as DRI cargo to select inert gas systems. In the future, it will give an idea to investors who intend to carry this type of dangerous cargo with their ships on a regular and irregular basis to equip their ships with any inert gas system or to use port facility inert gas systems. Besides, systems that produce different noble gases that will not react with oxygen during the transportation of solid hazardous cargoes and that will be used for the same purpose can be developed, and the alternatives can be increased in the future studies.

\section{Conclusions}

Safe cargo transportation is significant for human lives, economy, and environment. In this study, we analyze the decision-making process of inert gas system selection to minimize the risks of DRI transportation that requires a safe transportation procedure because of its risks and danger such as ignition, explosion, and fire. The IF-TOPSIS method is used to conduct the selection process step by step. We have determined criteria and alternatives, and the data are obtained by the help of field expert consultations. The study shows that port facility nitrogen generator is the best prominent alternative. Due to its nature, maritime transport is different from other transport sectors in that it is possible to transport huge amounts of dangerous goods at once. Therefore, additional measures should be taken for safe sea transport. Besides, in this study, it is predicted that safety measures should be increased to ensure safe sea transportation. Inerting is one of the primary safety precautions against the dangers of DRI cargo and similar cargo, which is one of the solid dangerous cargoes carried by sea. Choosing the inert gas system to be used in this critical process is a difficult and complex problem. Sufficient research studies have not been conducted on the problem of choosing the inert gas system for the transportation of solid dangerous goods such as DRI cargo by ships. Since inert gas systems are the systems used in ships carrying chemical liquid cargo and petroleum products, companies that own bulk/dry cargo ships do not equip these systems to their ships. When it comes to carrying solid cargoes such as DRI, the need for inert gas arises. This need is generally met from external systems. In the case of short-term travel situations, transportation is carried out without inerting systems from time to time.

In the study, the problem of choosing inert gas systems as a safety precaution against solid hazardous cargoes for maritime companies operating in the world's seas and 
engaged in bulk/dry cargo transportation is addressed. To reduce the addressed risks of ignition, explosion, and fire in cargo holds for DRI cargo, the research has been aimed to choose the most suitable inert gas system from widely used five inert gas systems among the maritime transportation sector. To solve the problem, first of all, the dangers of the DRI load and the conditions of carrying this load are examined. Besides, suitable inert gas systems are researched for comparison purposes. By creating selection criteria for the current inert gas systems in the sector, the problem is addressed with IF-TOPSIS method for solution. Multi-criteria decision-making methods are actually processes that assist in decision making and include subjective criteria. Therefore, alternatives may have clear advantages over each other, as well as similar results to each other. Moreover, criterion weighting on the results is important. In the present method, the rates obtained for the alternatives enable us to make a comparison and rank among the candidate systems. As a result of the study, the port facility independent inert gas generator system becomes more dominant than the other alternatives.

\section{Data Availability}

The data used to support the findings of this study are available from the corresponding author upon request.

\section{Conflicts of Interest}

The authors declare that they have no conflicts of interest.

\section{Acknowledgments}

We appreciate Prof. Dr. Ahmet Soylu for his valuable suggestions in conducting this study. We also thank the anonymous professionals who contributed to this study by providing answers to the surveys.

\section{References}

[1] S. Çetinyokuş, "Analysis of accidents related to maritime transport of dangerous goods," Journal of Humanities and Tourism Research, vol. 10, pp. 41-54, 2020.

[2] IMSBC Code and Supplement, International Maritime Solid Bulk Cargoes \& Supplement 2020, IMO Publications, London, UK, 2020.

[3] A. N. Sitov, V. A. Malovechko, and A. E. Slitsan, "Sea transportation of direct reduced iron in bulk," Vestnik Gosudarstvennogo universiteta morskogo $i$ rechnogo flota imeni admirala SO Makarova, vol. 10, pp. 1162-2117, 2018.

[4] M. K. Paswan and C. Mukherjee, "Economic analysis of transportation directly reduced iron (dri) through ship," International Journal of Services Technology and Management, vol. 17, no. 2/3/4, pp. 251-266, 2012.

[5] ICS OCIMF, International Safety Guide for Oil Tankers and Terminals (ISGOTT), OCIMF, London, UK, 2006.

[6] B. Ünver, S. Gürgen, B. Sahin, and İ. Altın, "Crankcase explosion for two-stroke marine diesel engine by using fault tree analysis method in fuzzy environment," Engineering Failure Analysis, vol. 97, pp. 288-299, 2019.
[7] N. Yildiz, "Sponge iron production," Mining Turkey Journal, vol. 42, pp. 90-96, 2014.

[8] F. C. Demirci, Investigation of carbothermic reduction reaction of continuous cast scale, Ph.D. thesis, Istanbul Technical University, Institute of Science and Technology, İstanbul, Turkey, 2010.

[9] International Iron Metallics Association (IIMA), DRI Production, Buckinghamshire, UK, 2020, https://www.metallics. org/dri-production.html.

[10] IMO, Inert Gas Systems, IMO Publishing, London, UK, 1990.

[11] A. Bandopadhyay, A. Ganguly, K. N. Gupta, and H. S. Ray, "Investigations on the anomalous oxidation behaviour of high-carbon gas-based direct reduced iron (dri)," Thermochimica Acta, vol. 276, pp. 199-207, 1996.

[12] P. E. Duarte, J. Becerra, C. Lizcano, and A. Martinis, "Energiron direct reduction technology-economical, flexible, environmentally friendly," Acero Latinoamericano, vol. 6, pp. 52-58, 2008.

[13] J. Li and M. Barati, "Kinetics and mechanism of decarburization and melting of direct-reduced iron pellets in slag," Metallurgical and Materials Transactions B, vol. 40, no. 1, pp. 17-24, 2009.

[14] M. Thomas and R. Skjong, "Cost benefit analysis of inert gas systems for chemical and product tankers," in Proceedings of the 28th International Conference on Offshore Mechanics and Arctic Engineering, pp. 651-660, Honolulu, HI, USA, May 2009.

[15] A. Sawada and T. Mitamoto, "Overview of market for direct reduced iron,” Kobelco Technology Review, vol. 29, pp. 47-49, 2010.

[16] J. K. Ahmad, "Using water hydrogen instead of reducing gas in the production of direct reduced iron (dri)," Journal of Advanced Oxidation Technologies, vol. 13, pp. 124-129, 2010.

[17] H. Tsutsumi, S. Yoshida, and M. Tetsumoto, "Features of fastmet process," Kobelco Technology Review, vol. 12, pp. 85-92, 2010.

[18] P. P. Ikubanni, A. A. Adeleke, O. O. Agboola et al., "Characterization of some commercially available nigerian coals as carbonaceous material for direct reduced iron production," Materials Today: Proceedings, vol. 44, pp. 2849-2854, 2021.

[19] J. Li, Z. Liang, L. Yi et al., "Novel insights into the reoxidation of direct reduced iron (dri) during ball-mill treatment: a combined experimental and computational study," Applied Surface Science, vol. 552, p. 149485, 2021.

[20] J. Safarian, "Duplex process to produce ferromanganese and direct reduced iron by natural gas," ACS Sustainable Chemistry \& Engineering, vol. 9, no. 14, pp. 5010-5026, 2021.

[21] S. Abd Elmomen, "Reoxidation of direct reduced iron in stagnant air in the temperature range between 150 and $450^{\circ} \mathrm{C}$," The Bulletin Tabbin Institute for Metallurgical Studies (TIMS), vol. 109, pp. 72-86, 2021.

[22] R. Leśmian-Kordas and M. Bojanowska, "Quality determinants of solid bulk cargoes in marine transport," Zeszyty Naukowe/Akademia Morska w Szczecinie, vol. 26, no. 98, pp. 66-74, 2011.

[23] I. Djadjev, "The evolving law and regulation of the carriage of dangerous goods by sea-the IMDG code and the IMSBC code," SSRN Electric Journal, vol. 2015, pp. 1-8, 2015.

[24] E. Akyuz, "Quantification of human error probability towards the gas inerting process on-board crude oil tankers," Safety Science, vol. 80, pp. 77-86, 2015.

[25] J. H. Heo and J. H. Park, "Effect of direct reduced iron (dri) on dephosphorization of molten steel by electric arc furnace 
slag," Metallurgical and Materials Transactions B, vol. 49, no. 6, pp. 3381-3389, 2018.

[26] H. Mandova, Assessment of bioenergy as a CO2 emission reduction strategy for European iron and steelmaking, Ph.D. thesis, University of Leeds, Leeds, England, 2019.

[27] B. Li, G. Sun, S. Li, H. Guo, and J. Guo, "The preparation of high-purity iron $(99.987 \%)$ employing a process of direct reduction-melting separation-slag refining," Materials, vol. 13, p. 1839, 2020.

[28] A. Salaheldine Darwish, M. Salem Mansour, H. Farag, and K. H. Ezzat, "Applying lopa and fuzzy logic to identify sil requirement for safety critical functions in a direct reduction iron industry," Alexandria Engineering Journal, vol. 59, no. 5, pp. 3575-3585, 2020.

[29] A. M. Glushchenko, "Decarbonization of the steel industry: the role of state economic policy," The Problems of Economy, vol. 1, no. 43, pp. 340-347, 2020.

[30] G. Kim, Carbon concentration and the use of direct-reduced iron in ironmaking and steelmaking, Ph.D. thesis, Carnegie Mellon University, Pittsburgh, PA, USA, 2020.

[31] P. Paknahad, M. Askari, and S. A. Shahahmadi, "Cold-briquetted iron and carbon (cbic), investigation of steelmaking behavior," Journal of Materials Research and Technology, 2020.

[32] D. Koa $\beta$, "Cargo claims: delivery of cargo under fraudulent bill of landing,"Master's thesis, Department of Maritime Studies of the University of Piraeus, Piraeus, Greece, 2020.

[33] O. Dam, “Comparative study on the un test $n$ ' 5 application on cargoes that emit flammable gases similar to dri $c$ that requires ventilation," Athenea, vol. 1, no. 1, pp. 41-51, 2020.

[34] A. Sane, G. Buragino, A. Makwana, and X. He, Enhancing Direct Reduced Iron (DRI) for Use in Electric Steelmaking, Air Products and Chemicals, Inc., Allentown, PA, USA, 2020.

[35] S. Elango, "Life cycle assessment of coal based direct-reduced iron production in India," Master of Science thesis, KTH Industrial Engineering and Management, Stockholm, Sweden, 2020.

[36] N. Siswantoro, H. Prastowo, and F. Z. Rosyadi, "Modification of sea water scrubber system into fresh water of inert gas system on the crude oil tanker 85,000 dwt," International Journal of Marine Engineering Innovation and Research, vol. 5, 2020.

[37] F. Shen, X. Ma, Z. Li, Z. Xu, and D. Cai, "An extended intuitionistic fuzzy topsis method based on a new distance measure with an application to credit risk evaluation," Information Sciences, vol. 428, pp. 105-119, 2018.

[38] B. Sahin and A. Soylu, "Intuitionistic fuzzy analytical network process models for maritime supply chain," Applied Soft Computing, vol. 96, Article ID 106614, 2020.

[39] B. Sahin, T. L. Yip, P. H. Tseng, M. Kabak, and A. Soylu, "An application of a fuzzy TOPSIS multi-criteria decision analysis algorithm for dry bulk carrier selection," Information, vol. 11, no. 5 , p. $251,2020$.

[40] B. Sahin and S. Kum, "Route selection approach for vessels in ice covered waters," Marine Science and Technology Bulletin, vol. 3, no. 2, pp. 1-4, 2014 .

[41] F. E. Boran and D. Akay, "A biparametric similarity measure on intuitionistic fuzzy sets with applications to pattern recognition," Information Sciences, vol. 255, pp. 45-57, 2014.

[42] M. Adrián and J. González, "Inert gas production: N2 plant vs conventional plant," Journal of Maritime Research, vol. 12, pp. 11-18, 2015.

[43] ICS OCIMF, International Safety Guide for Oil Tankers and Terminals (ISGOTT), OCIMF, London, UK, 2020.
[44] E. Aykanat, Analysis of ship accidents with the help of port and flag state control data, Ph.D. thesis, DEU Institute of Science and Technology, Izmir, Turkey, 2010.

[45] F. Yilmaz and N. J. Ece, "Analysis of the relationship between the variables of paris mou-psc inspections applied to Turkish flagged ships and the inspection result," Journal of Eta Maritime Science, vol. 5, pp. 172-185, 2017.

[46] E. Celik and E. Akyuz, "An interval type-2 fuzzy ahp and topsis methods for decision-making problems in maritime transportation engineering: the case of ship loader," Ocean Engineering, vol. 155, pp. 371-381, 2018. 